\title{
HIGH MOLECULAR DERIVATIVES OF VITAMIN A
}

\author{
TADAO IDA, SHOJI TAKAHASHI AND ISAMU UTSUMI ${ }^{1}$ \\ Pharmaceutical Research Laboratory, \\ Tanabe Seiyaku Co., Ltd., Higashiyodogawa-ku, Osaka
}

(Received November 22, 1963)

Various derivatives of vitamin A, especially esters and ethers, have been studied by many investigators. However, its macromolecular derivatives have scarcely been reported. An attempt was made by the authors to synthesize the macromolecular derivatives of vitamin A by preparation of the polymerizable derivatives, followed by their polymerization. Thus vitamin A acrylate, methacrylate, crotonate, and undecylenate and their polymers were synthesized and their properties were studied.

Esterification of vitamin A alcohol was carried out by the reaction with acid chloride in the mixture of ethylene dichloride and pyridine by the method of Isler et al. (1) and Baxter et al. (2), or with acid anhydride by the method of Takahashi et al. (3). Each ester thus obtained was not isolated from unreacted vitamin A alcohol by extraction with solvent, such as $95 \%$ methanol and petroleum ether, but purified successfully by column chromatography of activated alumina using benzene solution, and viscous yellow fluids of pure esters were obtained. In this case pure esters of vitamin A were eluted quickly, but unreacted vitamin A alcohol and other impurities were adsorbed on alumina or eluted very slowly.

These esters were polymerized by the use of $\alpha, \alpha^{\prime}$-azo-bis-isobutyronitrile $(\mathrm{ABIN})$ as a catalyst of radical polymerization in nitrogen atmosphere at $70^{\circ}$, and yellow powdery polymers were obtained. Furthermore, the polymers were also obtained in good yield by the polymerization at low temperature, -10 to $-20^{\circ}$, using $n$-butyl lithium as a catalyst. By both the above methods, vitamin A acrylate and methacrylate were polymerized easily, but crotonate and undecylenate were not.

Polymerization of the esters using phenyl magnesium bromide as a catalyst at $0^{\circ}$ was also examined, but no polymer could be isolated. However, a spot at $R_{F}$ 0 was observed in paper chromatography using petroleum ether as a solvent and the papers pretreated with aluminium sulfate-ammonia. Therefore, the polymer seems to be produced partially.

Copolymers of vitamin A esters and other vinyl compounds were synthesized by the use of $A B I N$ as a catalyst for that with acrylic or methacrylic acid, and $n$-butyl lithium for that with methylacrylate methylmethacrylate, styrene or 2 vinyl-5-ethylpyridine.

The homopolymers and copolymers thus obtained were all yellow powdery

${ }^{1}$ 伊田忠夫, 高橋省二, 内海 甬. 
or resinous substances and failed to show clear melting points, for example, polyvitamin A methacrylate obtained by radical polymerization softened gradually from about 100 to $120^{\circ}$, then became clear slowly and decomposed over that temperature.

On the other hand, the polymers polymerized with $n$-butyl lithium were not decomposed over $300^{\circ}$. Therefore, the latter is considered to be more stereoregular in structure than others.

The monomers, homopolymers and copolymers were soluble in petroleum ether and chloroform, but insoluble in water. The copolymers with acrylic and methacrylic acid were soluble in methanol and ethanol, but insoluble in petroleum ether. Methanol and ethanol dissolved the monomers but not the homopolymers and other copolymers.

The results of the determination of vitamin A content by the method specified in U.S.P. XVI and glycerol dichlorohydrin method were as follows: poly-vitamin A methacrylate, $97 \%$; vitamin A methacrylate-methacrylic acid copolymer, $36.6 \%$; -styrene copolymer, $44.0 \%$; -2-vinyl-5-ethyl pyridine copolymer, $25.2 \%$ and vitamin A acrylate derivatives, almost the same values as the corresponding methacrylate derivatives.

In the paper chromatography using petroleum ether as a solvent and the paper pretreated with aluminium sulfate-ammonia, the monomers showed $R_{\mathrm{F}} 1.0$ and the polymers $R_{\mathrm{F}} 0$ in every case.

As shown in Fig. 1, infrared absorption spectra of the derivatives showed the absorptions of vitamin A structure and of the ester group in all the monomers and polymers, and the absorptions of vinyl group in the monomers. But in the polymers the absorptions of vinyl group were not observed and a slightly broad absorption spectrum was obtained.

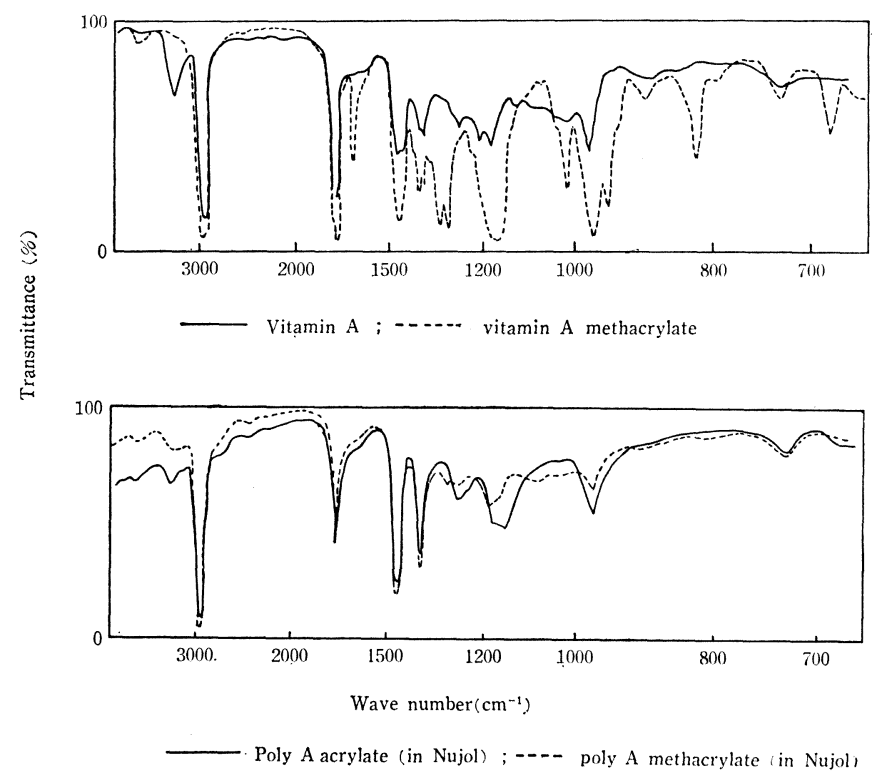

FIG. 1 Infrared Absorption Spectra of Vitamin A and Its Derivatives 
Ultraviolet absorption spectra of the derivatives showed the same curve having the maximum absorption at around $325 \mathrm{~m} \mu$ in all the derivatives as shown in Fig. 2 .

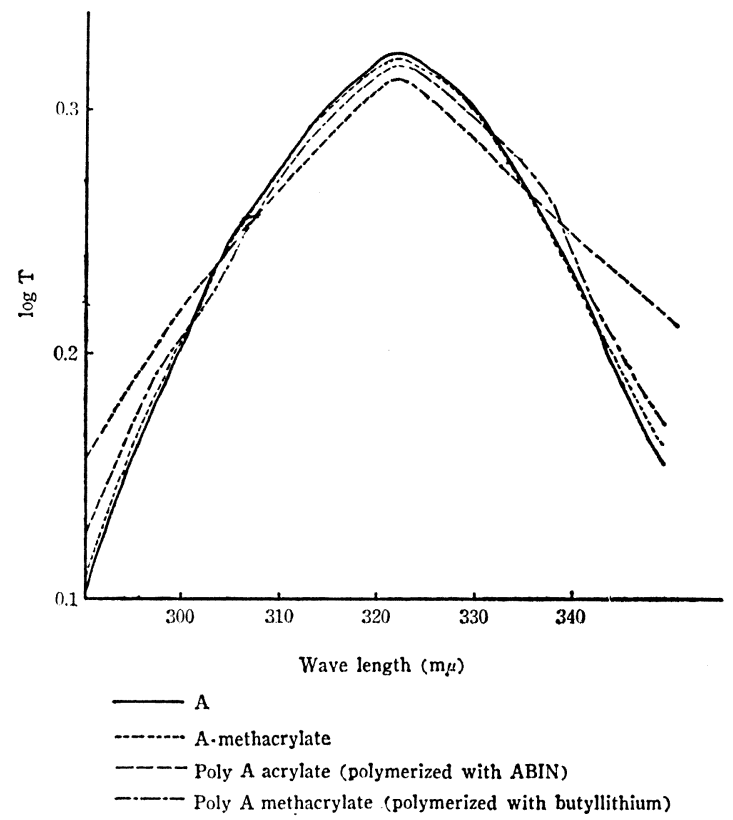

FIg. $2 U V$-Absorption Spectra of Viatmin $A$ and Its Derivatives (in $\mathrm{CHCl}_{3}$ )

The products of alkali hydrolysis of the macromolecular derivatives were colored with antimony trichloride and their infrared and ultraviolet absorption spectra were in agreement with that of vitamin A alcohol.

\section{EXPERIMENTAL}

\section{Vitamin $A(I)$}

"Vitamin AD oil", containing 1,000,000 U.S.P. unit per gram of vitamin A palmitate, was hydrolyzed with methanolic potassium hydroxide by the method of Isler et al. (1) and extracted with $95 \%$ methanol and petroleum ether.

2. Vitamin A Acrylate (II)

(a) Six grams of I and $4.5 \mathrm{ml}$ of pyridine were dissolved in $30 \mathrm{ml}$ of ethylene dichloride, and $2.2 \mathrm{~g}$ of acrylic chloride was added under ice-cooled condition. After allowing to stand for three hours at room temperature, the reactant was neutralized with $0.5 \mathrm{~N}$ sulfuric acid, then extracted with petroleum ether. Tne extract was washed with $0.5 \mathrm{~N}$ sulfuric acid, water, $10 \%$ potassium carbonate aqueous solution and $95 \%$ methanol in turn, and dried. After distillation of the solvent under reduced pressure, viscous oil thus obtained was dissolved in benzene and passed through the column of activated alumina. II was separated as the first golden yellow layer from the next dark orange layer of impurities. Each layer 
was eluted by benzene separately. $4.5 \mathrm{~g}$ of golden yellow oil was obtained after distillation of the solvent under reduced pressure.

(b) To a solution of $1.3 \mathrm{~g}$ of $\mathrm{I}$ in $1.5 \mathrm{ml}$ of pyridine, $1.3 \mathrm{ml}$ of acrylic anhydride was added, and allowed to stand for 20 hours at room temperature. The reactant was treated under the same condition as $a$, yielding $1.0 \mathrm{~g}$ of golden yellow oil.

Anal. Calcd. for $\mathrm{C}_{23} \mathrm{H}_{32} \mathrm{O}_{2}$ : C, 81.12; H, 9.47. Found: C, 81.01; H, 9.53.

3. Vitamin A Methacrylate (III)

Two grams of I, $800 \mathrm{mg}$ of methacrylic chloride, $2 \mathrm{ml}$ of pyridine and $30 \mathrm{ml}$ of ethylene dichloride were used, and treated as $2 a$, yielding $2.1 \mathrm{~g}$ of golden yellow oil of III.

Anal. Calcd. for $\mathrm{C}_{24} \mathrm{H}_{34} \mathrm{O}_{2}$ : C, 81.30; H, 9.67. Found: C, 81.05; H, 9.50.

4. Vitamin A Crotonate (IV)

In the mixture of ethylene dichloride and pyridine, $3.4 \mathrm{~g}$ of I was allowed to react with $1.3 \mathrm{~g}$ of crotonyl chloride and treated by the same procedure as $2 a$, yielding. $1.6 \mathrm{~g}$ of golden yellow oil.

Anal. Calcd. for $\mathrm{C}_{24} \mathrm{H}_{34} \mathrm{O}_{2}$ : C, $81.30 ; \mathrm{H}, 9.67$. Found: C, 82.10; H, 9.72 .

5. Vitamin A Undecylenate $(V)$

Two grams of I was allowed to react with $1.6 \mathrm{~g}$ of undecylenyl chloride in the mixture of ethylene dichloride and pyridine, and treated similarly, yielding 3.1 $\mathrm{g}$ of golden yellow oil.

Anal. Calcd. for $\mathrm{C}_{31} \mathrm{H}_{48} \mathrm{O}_{2}$ : C, 82.24; H, 10.69. Found: C, 82.01; H, 10.60 .

6. Poly-Vitamin A Acrylate (VI)

(a) In a small amount of $n$-hexane $2.0 \mathrm{~g}$ of II was dissolved, and put into brown colored tube with $20 \mathrm{mg}$ of ABIN. After distillation of solvent under reduced pressure, the tube was sealed after replacing air with nitrogen. Then the mixture in the tube was polymerized for 20 hours at $70^{\circ}$. The reactant was dissolved in ether and poured into $95 \%$ methanol to precipitate the polymer. The polymer was purified by reprecipitation and $600 \mathrm{mg}$ of yellow powdery substance was obtained.

(b) To a solution of $3.5 \mathrm{~g}$ of II in $25 \mathrm{ml}$ of $n$-hexane, $0.8 \mathrm{ml}$ of $n$-butyl lithium solution, corresponding to 0.0005 mole, was added at -10 to $-20^{\circ}$, under stirring for three hours. After standing for 17 hours at -5 to $-10^{\circ}$, the reaction was stopped by the addition of a small amount of methanol, then a large amount of methanol was added to precipitate the yellow colored polymer. After reprecipitation with ether and methanol, $1.4 \mathrm{~g}$ of yellow powdery substance was obtained.

(c) In $35 \mathrm{ml}$ of toluene $3.3 \mathrm{~g}$ of II was dissolved, and $0.15 \mathrm{ml}$ of ether solution of phenyl magnesium bromide, corresponding to 0.00015 mole was added at $0^{\circ}$. After reaction for 48 hours, the reactant was poured into a large amount of methanol, but nothing was precipitated. Paper chromatography showed the production of polymer, but any efforts to separate the polymer did not succeed.

7. Poly-Vitamin A Methacrylate (VII)

(a) By the use of $20 \mathrm{mg}$ of ABIN, $2 \mathrm{~g}$ of III was polymerized for 40 hours at $70^{\circ}$ by the same method as 5 a. Yellow powder of $400 \mathrm{mg}$ was obtained.

(b) Two grams of III was polymerized with $n$-butyl lithium as 5 b. $700 \mathrm{mg}$ of 
yellow powdery substance was obtained.

(c) The same polymerization by the catalyst of phenyl magnesium bromide as $5 c$ was applied to $2.0 \mathrm{~g}$ of III, but no polymer was obtained, though paper chromatography showed the presence of polymer.

\section{Copolymer with Vinyl Compound}

The condition of copolymerization of vitamin A acrylate or methacrylate with various vinyl compounds was summerized in Table I and II. In these Tables copolymerization by the use of ABIN was proceeded similarly to $5 a$, and then the copolymer was precipitated by the addition of petroleum ether to methanol or ether solution of the reactant. In the case of using $n$-butyl lithium as a catalyst, the same method as $5 b$ was applied. The copolymers were all yellow powdery substances.

TABLE I

Copolymerization of Vitamin A Acrylate with Vinyl Compounds

\begin{tabular}{|c|c|c|c|c|c|c|c|}
\hline Comonomer & & $\begin{array}{c}\text { Acrylic } \\
\text { acid }\end{array}$ & $\begin{array}{c}\text { Methacrylic } \\
\text { acid }\end{array}$ & $\begin{array}{c}\text { Methyl } \\
\text { acrylate }\end{array}$ & $\begin{array}{c}\text { Methyl } \\
\text { methacrylate }\end{array}$ & $\begin{array}{l}\text { 2-Vinyl-5- } \\
\text { ethylpyridine }\end{array}$ & Styrene \\
\hline A-acrylate & & 1.0 & 1.0 & 1.0 & 1.0 & 1.0 & 1.0 \\
\hline Comonomer & $(m g)$ & 200 & 250 & 200 & 300 & 350 & 300 \\
\hline Catalyst & $(m g)$ & ABIN 10 & ABIN 10 & $0.1^{a}$ & $0.1^{a}$ & $0.1^{a}$ & $0.1^{a}$ \\
\hline n-Hexane & $(m l)$ & - & - & $\begin{array}{l}3 \\
-\end{array}$ & -3 & 3 & 3 \\
\hline Temperature & $\left({ }^{\circ} \mathrm{C}\right)$ & 60 & 60 & $0-5$ to -10 & $0^{b}-5$ to $-10^{b}$ & -5 to $-10^{b}$ & -5 to $-10^{b}$ \\
\hline Time & $(h r)$ & 40 & 40 & 16 & 16 & 16 & 16 \\
\hline Yield & $(m g)$ & 250 & 250 & 400 & 300 & 500 & 350 \\
\hline A content & (9) & 22.0 & 30.4 & 29.6 & 31.4 & 26.4 & 29.3 \\
\hline
\end{tabular}

a $6.4 \% n$-butyl lithium petroleum ether solution. ${ }^{\circ}$ Catalyst was added at -10 to $-20^{\circ}$, then stirred for $2 \mathrm{hr}$.

TABLE II

Copolymerization of Vitamin A Methacrylate with Vinyl Compounds

\begin{tabular}{|c|c|c|c|c|c|c|c|}
\hline Comonomer & & $\begin{array}{l}\text { Acrylic } \\
\text { acid }\end{array}$ & $\begin{array}{c}\text { Methacrylic } \\
\text { acid }\end{array}$ & $\begin{array}{l}\text { Methyl } \\
\text { acrylate }\end{array}$ & $\begin{array}{c}\text { Methyl } \\
\text { methacrylate }\end{array}$ & $\begin{array}{l}\text { 2-Vinyl-5- } \\
\text { ethylpyridine }\end{array}$ & Styrene \\
\hline A-acrylate & & 1.0 & 1.0 & 1.0 & 1.0 & 1.0 & 1.0 \\
\hline Comonomer & $(m g)$ & 200 & 250 & 200 & 300 & 350 & 300 \\
\hline Catalyst & $(m g)$ & $\mathrm{ABIN} 10$ & $\mathrm{ABIN} 10$ & $0.1^{a}$ & $0.1^{a}$ & $0.1^{a}$ & $0.1^{a}$ \\
\hline$n$-Hexane & $(m l)$ & - & - & 3 & 3 & 3 & 3 \\
\hline Temperature & $\left({ }^{\circ} \mathrm{C}\right)$ & 60 & 6 & -5 to $-10^{b}$ & -5 to $-10^{b}$ & -5 to $-10^{b}$ & -5 to $-10^{b}$ \\
\hline Time & $(h r)$ & 40 & 40 & 16 & 16 & 16 & 16 \\
\hline Yield & $(m \mathrm{~g})$ & 200 & 250 & 200 & 350 & 400 & 300 \\
\hline A content & $(96)$ & 24.1 & 27.6 & 28.8 & 33.6 & 25.2 & 44.0 \\
\hline
\end{tabular}

a $6.4 \%$ Butyl lithium petroleum ether solution. ${ }^{b}$ Catalyst was added at -10 to $-20^{\circ}$, then stirred for $2 \mathrm{hr}$.

\section{SUMMARY}

Powdery polymers of vitamin A esters were synthesized by polymerizing acrylic and methacrylic ester of vitamin $\mathrm{A}$ under the presence of $\alpha, \alpha^{\prime}$-azo-bis-isobutyronitrile as a catalyst at $70^{\circ}$ or of $n$-butyl lithium in hexane at -10 to $-20^{\circ}$. The polymer failed to be obtained when phenyl magnesium bromide was used as a 
catalyst. Crotonic and undecylenic esters of vitamin A were not polymerized by the above methods. Powdery copolymers of vitamin A esters with acrylic acid, methacrylic acid, methyl acrylate, methyl methacrylate, styrene or 2-vinyl-5-ethylpyridine were also synthesized by the same methods.

\section{REFERENCE}

1. Isler, O., Ronco, A., Guex, W., Hindley, N.C., Hubei, W., Dialer, K., and Kofler, M., Helv. Chim. Acta 32, 489 (1949).

2. Baxter, J.C., and Robeson, C.D., J. Amer. Chem. Soc. 64, 2410 (1942).

3. Takahashi, K., Nakamiya, J., Kawakami, K., and Kitazato, T., Riken Iho 3, 693 (1924). 